\title{
A 1000-year simulation with the IPSL ocean-atmosphere coupled model
}

\author{
Zhao X. Li and Sébastien Conil \\ Laboratoire de Météorologie Dynamique, CNRS, Université Pierre et Marie Curie, Paris, France
}

\begin{abstract}
A 1000-year climate simulation is run with the ocean-atmosphere coupled model developed at the Institute PierreSimon Laplace (IPSL, Paris). No flux adjustment is used. The drift of the model is analyzed in terms of the seasurface temperature and deep ocean temperature. When the model's own equilibrium is reached, it is found that the Antarctic bottom water production experiences large-amplitude variation, oscillating between strong and weak episodes. This can yield oceanic temperature variation in the Southern Hemisphere and for the global mean.
\end{abstract}

Key words coupled climate model - long-term climate simulation - oceanic overturning circulation model drift

\section{Introduction}

Ocean-atmosphere coupled general circulation models have become a very useful tool for either climate natural variability studies or future anthropegenic climate change prediction. However, such models have in general important drift when used to simulate current climate, due to mutual amplification of the shortcomings in the oceanic and atmospheric models. An earlier approach to reduce the drift was to use a procedure called flux adjustment by introducing artificially flux compensation at the air-sea interface. Recent coupled models, however, try to improve the parametrisation in order to reduce the drift. In the framework of the SINTEX european project, the IPSL (Institut Pierre-Simon

Mailing address: Dr. Zhao X. Li, Laboratoire de Météorologie Dynamique, CNRS, Université Pierre et Marie Curie, casier 99, 4 place Jussieu, 75252 Paris cedex 05, France; e-mail: li@lmd.jussieu.fr
Laplace) has built up such an ocean-atmosphere coupled model without any flux adjustment. This paper describes the basic behaviours of the model in a 1000-year long simulation.

\section{Model and simulation}

The IPSL coupled model involves the atmospheric GCM (LMDZ) developed at LMD (Laboratoire de Météorologie Dynamique, Paris) and the oceanic GCM (ORCA) developed at LODYC (Laboratoire d'Océanographie Dynamique et Climat, Paris).

In this study, the version 3.2 of LMDZ is used. It is derived from the standard version described in Sadourny and Laval (1984). The model is formulated in the finite-difference grid with a horizontal resolution of 5 by 4 degrees in longitude and latitude directions and 19 hybrid vertical layers. A brief description of the physical parameterization and the model's main performance in simulating interannual climate variability are presented in Li (1999).

The model has evolved in the following points. The convection scheme is a simple massflux scheme. The closures (both triggering condition and entrainment/detrainment rate) 
are based on the surface evaporation and largescale water-vapor convergence. The cloud parameterization is a prognostic scheme, as described in Le Treut and Li (1991). At present, only clouds associated with stratiform precipitation are taken into account. Those created by convection are diagnosed following the intensity of convective precipitation. The surface model is a bucket model for which we consider a homogeneous layer of $150 \mathrm{~mm}$. The calculation of the surface temperature is incorporated in the boundary layer and based on the surface energy balance equation. For the surface moisture, a holding capacity is fixed at $150 \mathrm{~mm}$ of water, and all the water above this value is lost as runoff.

ORCA is the global version of the OPA 8.1 ocean modelling system developed by the LODYC team in Paris (Madec et al., 1998). A full documentation is available at http://www. lodyc.jussieu.fr/opa). It is a finite difference OGCM formulated on the C-grid. The present configuration uses a rigid lid. The horizontal mesh is orthogonal and curvilinear on the sphere. To overcome the singularity at the North Pole, the northern point of convergence has been replaced by two poles located in Asia and North America. Its space resolution is roughly equivalent to a geographical mesh of 2 by 1.5 degrees (with a meridional resolution of 0.5 degrees near the Equator). 31 vertical levels are used with 10 levels in the top 100 metres. Vertical eddy diffusivity and viscosity coefficients are computed from a 1.5 turbulent closure scheme. Horizontal mixing of momentum is of Laplacian type with an eddy viscosity coefficient of 40000 $\mathrm{m}^{2} / \mathrm{s}$, reduced in the Tropics to $2000 \mathrm{~m}^{2} / \mathrm{s}$ at the Equator. The lateral mixing of tracers (temperature and salinity) is isopycnal as described in Guilyardi et al. (2001). The version used here does not have an interactive sea-ice model and sea-ice cover is relaxed towards observed monthly climatology.

LMDZ and ORCA are coupled through OASIS (Valcke et al., 2000). The coupling procedure is identical to the SINTEX coupled model (Gualdi et al., 2003) involving the same oceanic model, but the ECHAM4 atmospheric model. From Levitus (1982), the model is integrated for 2 years in the robust-diagnostic mode. Once the oceanic dynamics is spun-up, the integration continues without any adjustment nor restoring (except in regions where sea-ice cover does not agree with climatology). Air-sea fluxes and SST are exchanged every $3 \mathrm{~h}$. The simulation was integrated for 1000 years.

\section{Results}

\subsection{Sea surface temperature}

Global and annual mean of the sea-surface temperature in function of time is plotted in the top panel of fig. 1. Other curves of fig. 1 display the SST evolution for respectively the Northern Hemisphere $\left(30 / 90^{\circ} \mathrm{N}\right)$, the tropics $\left(30^{\circ} \mathrm{S} / 30^{\circ} \mathrm{N}\right)$ and the Southern Hemisphere $\left(30 / 90^{\circ} \mathrm{S}\right)$. To facilitate visual inspection, the range for $Y$ axis is kept constant ( 3 degrees) for all the plots.

For the global mean, the SST has a cooling of about $0.6 \mathrm{~K}$ for the first 50 years. This is the rapid model drift at the initial stage, also visible in the Tropics and the Southern Hemisphere. After this initial drift, the tropics remain relatively stable for the whole simulation and highfrequency variation can be observed. Longperiod variation is quite well linked with that of the Southern Hemisphere. From the simulated year 50 to 300, the Southern Hemisphere experiences a slow drift to the warm. This is also observed in the tropics and in the global mean. The Northern Hemisphere has particular behaviour with an initial warming drift during the first 110 years and then a slow cooling that lasts until the year 500. Decadal-scale variation can be observed for the Northern Hemisphere.

After the initial quick and slow drift periods, the coupled system reaches its own equilibrium state. A remarkable phenomenon is the largeamplitude SST variation for the Southern Hemisphere. For example, there is a drop of $1^{\circ} \mathrm{C}$ from the year 470 to 520 and a similar amplitude warming from the year 720 to 770 . The global mean is also influenced by these episodes and the amplitude can reach $0.4^{\circ} \mathrm{C}$. We will show later that the SST variation is correlated to the oceanic convection in the Southern Ocean and the associated overturning circulation.

We examine now the global distribution of the simulated SST. The top panel of fig. 2 shows 

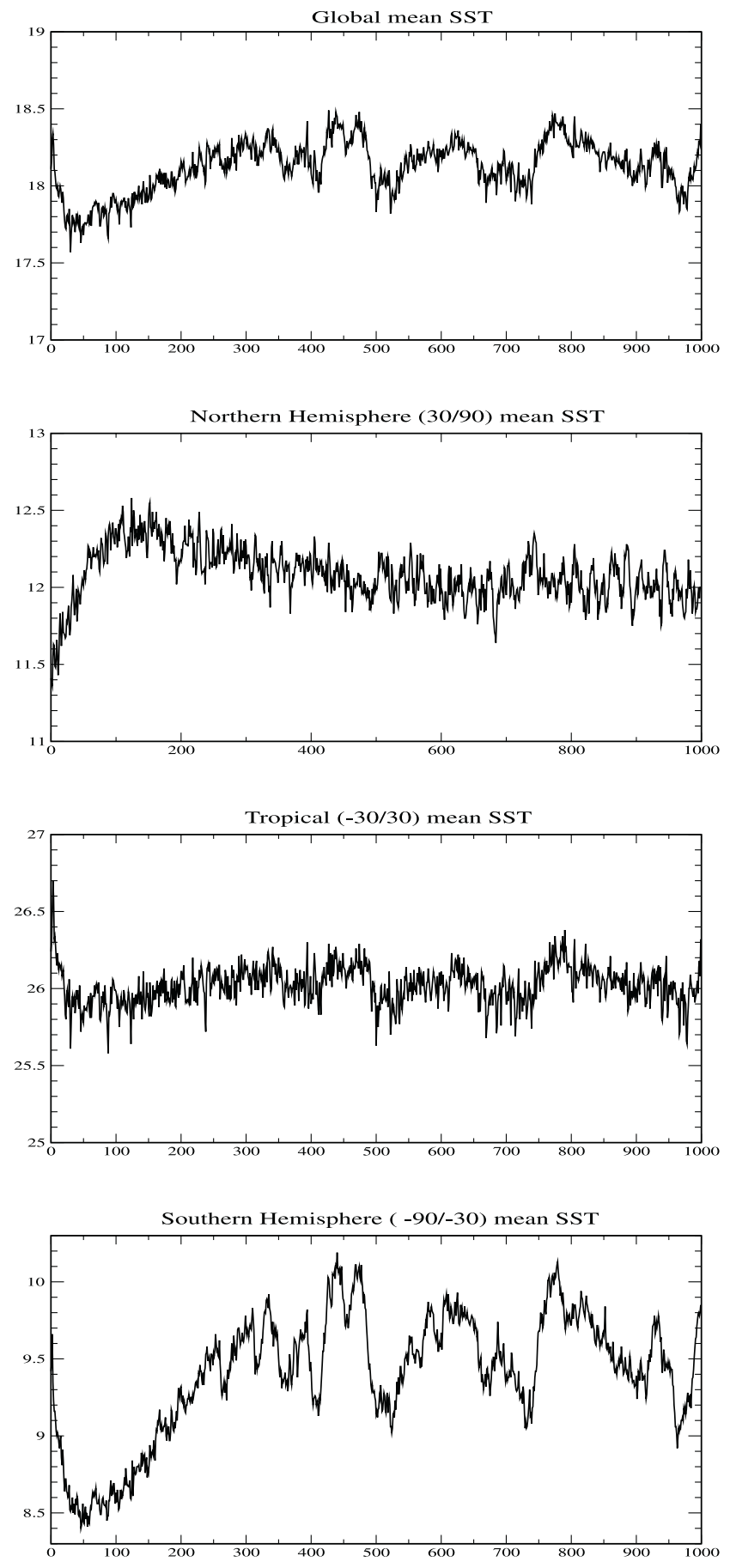

Fig. 1. Mean sea-surface temperature $\left({ }^{\circ} \mathrm{C}\right)$ in function of simulated year for (from top to bottom) the whole globe, the Northern Hemisphere $\left(30 / 90^{\circ} \mathrm{N}\right)$, the tropics $\left(30^{\circ} \mathrm{S} / 30^{\circ} \mathrm{N}\right)$ and the Southern Hemisphere $\left(30 / 90^{\circ} \mathrm{S}\right)$.

the difference between the simulated SST from the year 901 to 1000 and the observed SST deduced from the HadISST 1.1 data set (Rayner et al., 1999) for the last 100 years. Warming drift is observed in the high latitudes of both the hemispheres: $2^{\circ} \mathrm{C}$ for the Southern Ocean and the North Pacific, $5^{\circ} \mathrm{C}$ for the North Atlantic in the Labrador Sea. Cooling is observed in the mid latitudes: 2 to $3^{\circ} \mathrm{C}$ from 20 to $40^{\circ} \mathrm{N}$ in the North Pacific and North Atlantic, 3 to $4^{\circ} \mathrm{C}$ from 30 to $50^{\circ} \mathrm{S}$ in the Southern Ocean. The tropical Indian Ocean has near-zero drift and the drift of the warm pool in the Western tropical Pacific is also small (around $-1^{\circ} \mathrm{C}$ ). The Tropical Atlantic has a cooling of 1 to $2^{\circ} \mathrm{C}$. Many coupled models have too warm SST in the western part of the subtropical oceanic basins, due to insufficient low-level cloud cover. From fig. 2 we can observe that there is almost no drift in the subtropical Atlantic near the African coast. This is certainly related to the recent improvements implemented in the boundary-layer parameterization. However the American coast in the subtropical Pacific still has a large warming drift (up to $4{ }^{\circ} \mathrm{C}$ ). The bottom panel of fig. 2 shows the SST difference between two periods of the simulation, the first one is from the year 3 to 10 and the second one is from year 901 to 1000 . It is clear that the initial drift (much larger than the interdecadal variations) during the first 10 years takes a large part of the final model drift. For the setup of coupled simulations, it is thus very important to check the initial results before running longer times.

\subsection{Deep ocean evolution}

Due to the overwhelming information for the three-dimensional ocean temperature, we have to apply a procedure to reduce the amount of information. To do so, we first make a horizontal grid transformation and interpolate the oceanic model output into the grid of the atmospheric model (a regular grid of 5 by 4 degrees in longitude and latitude). Then a principal component analysis is applied to the interpolated 3-dimensional oceanic temperature with a normalization by the cosine of the latitude and the depth of each layer.

Figure 3 shows the obtained leading spatial structure (EOF) and the time-varying coefficient (PC). It accounts for $76 \%$ of the total variance. For graphic-display purpose, the spatial structure 
SST drift (reference: Hadisst) for 901/1000

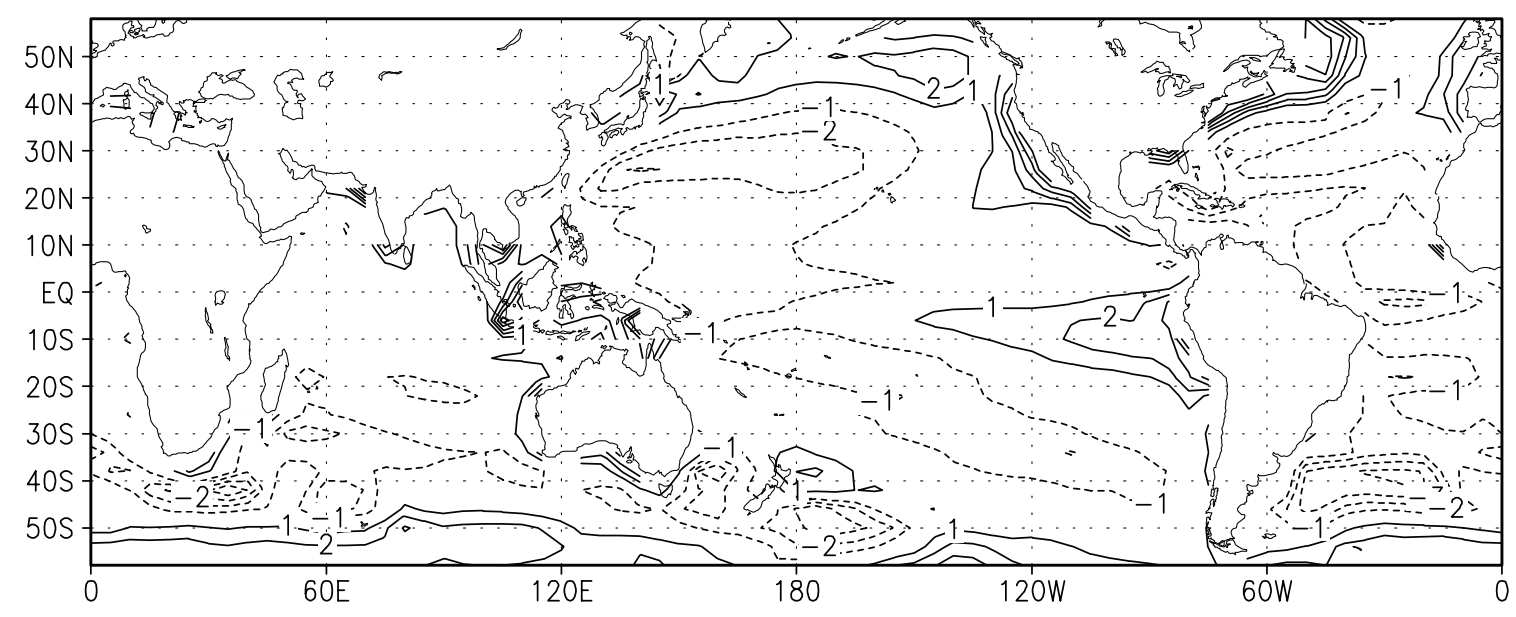

SST drift from $3 / 10$ to $901 / 1000$

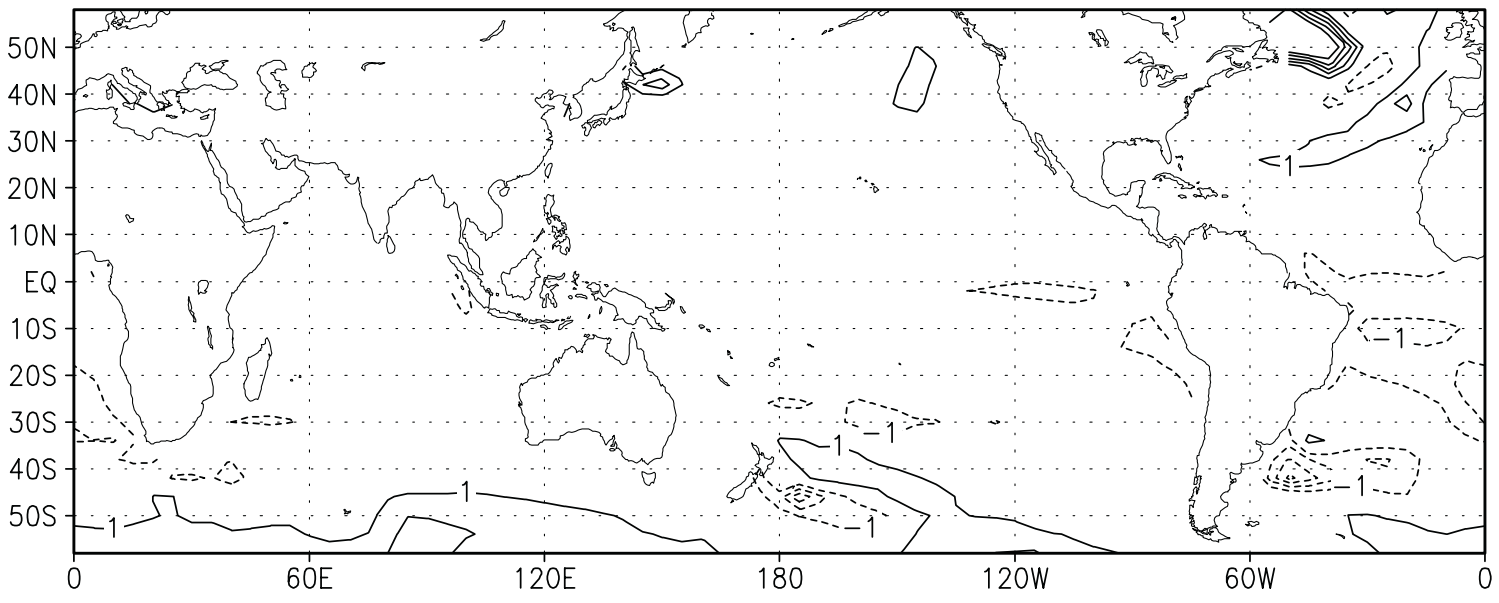

Fig. 2. Top: difference of the sea-surface temperature $\left({ }^{\circ} \mathrm{C}\right)$ between the simulation (averaged over 901/1000) and the observation (HadISST1.1, averaged over 1900/1999). Bottom: difference of the sea-surface temperature $\left({ }^{\circ} \mathrm{C}\right)$ between two periods of the simulation $(901 / 1000$ - 3/10).

is plotted for different oceanic basins (Indian Ocean, Pacific and Atlantic) after making the zonal average. For the three oceanic basins, there is a dipole contrast between the upper layers and the deep ones. Taking into account the negative evolution of the $\mathrm{PC}$ from the beginning until the year 700, the most important oceanic temperature drift is a deep-ocean warming and a cooling in the surface layer of about $1000 \mathrm{~m}$. Figure 4 shows the second EOF and corresponding PC, which accounts for $13 \%$ of the total variance. We can observe a contrast between the Atlantic at one hand and the Pacific and Indian Ocean at the other hand. It is probably related to the variation in the global thermohaline circulation. The PC curve shows a decrease from the beginning until the year 300 and then a recovering until the year 800 .

\subsection{Southern ocean and North Atlantic overturning circulation}

The top panel of fig. 5 shows the global overturning circulation stream function for the last one hundred years of the simulation. It indicates the zonally-averaged mass transport in 

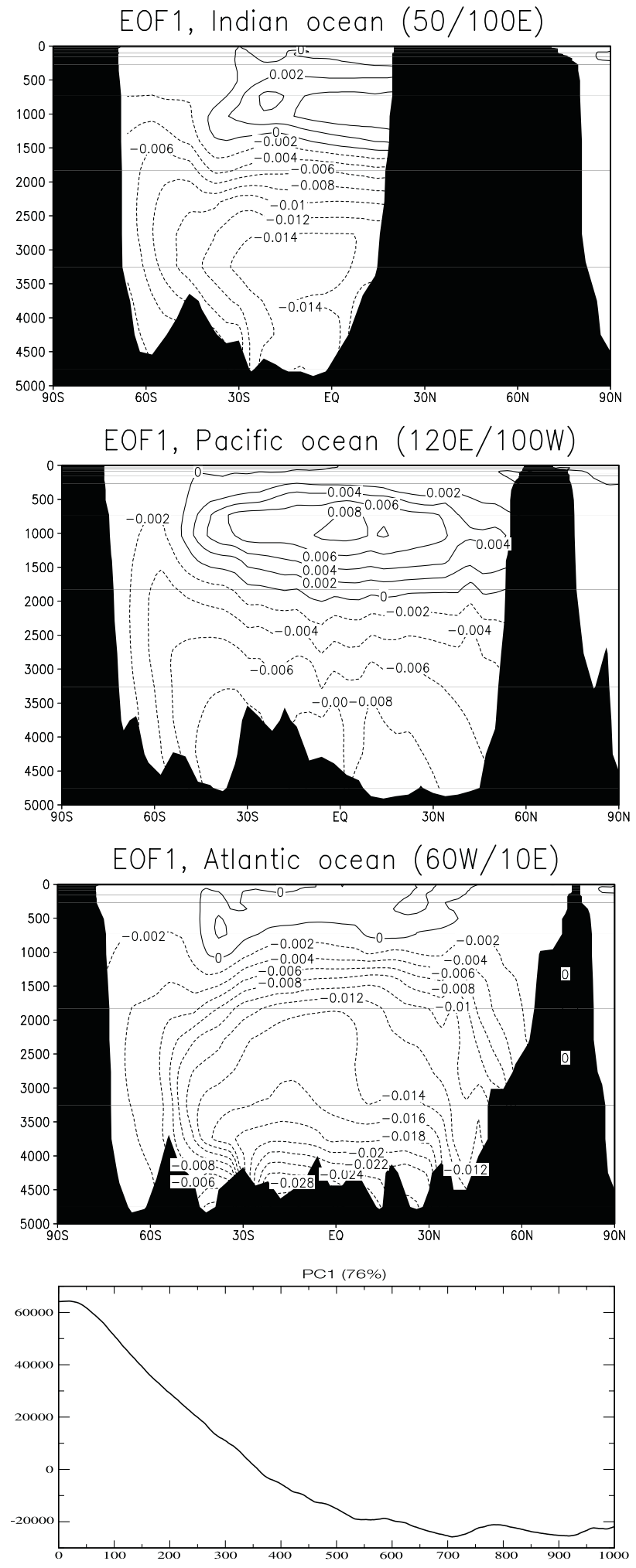

(3)

Fig. 3. Spatial structure and time series (arbitrary units) of the leading Empirical Orthogonal Function (EOF) for the 3-dimensional oceanic temperature. The spatial structure is plotted separately for the three basins in the form of zonal average.

Fig. 4. Same as in fig. 3, but for the second EOF.

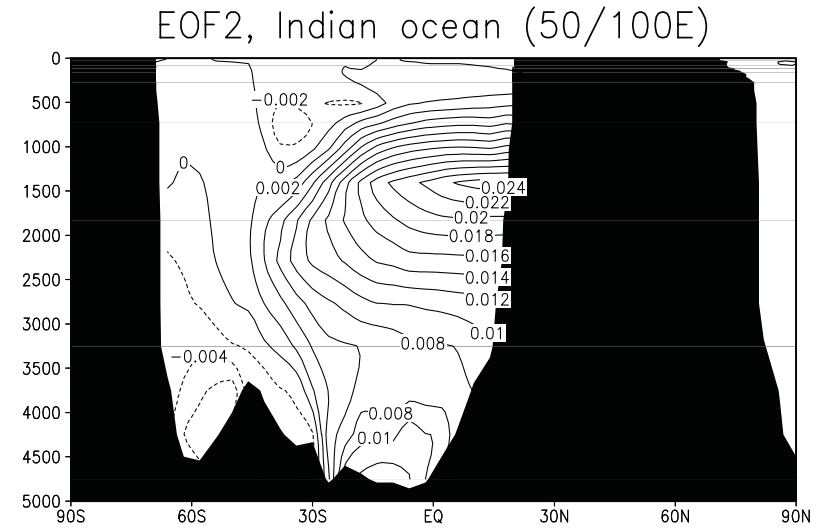

EOF2, Pacific ocean (120E/100W)
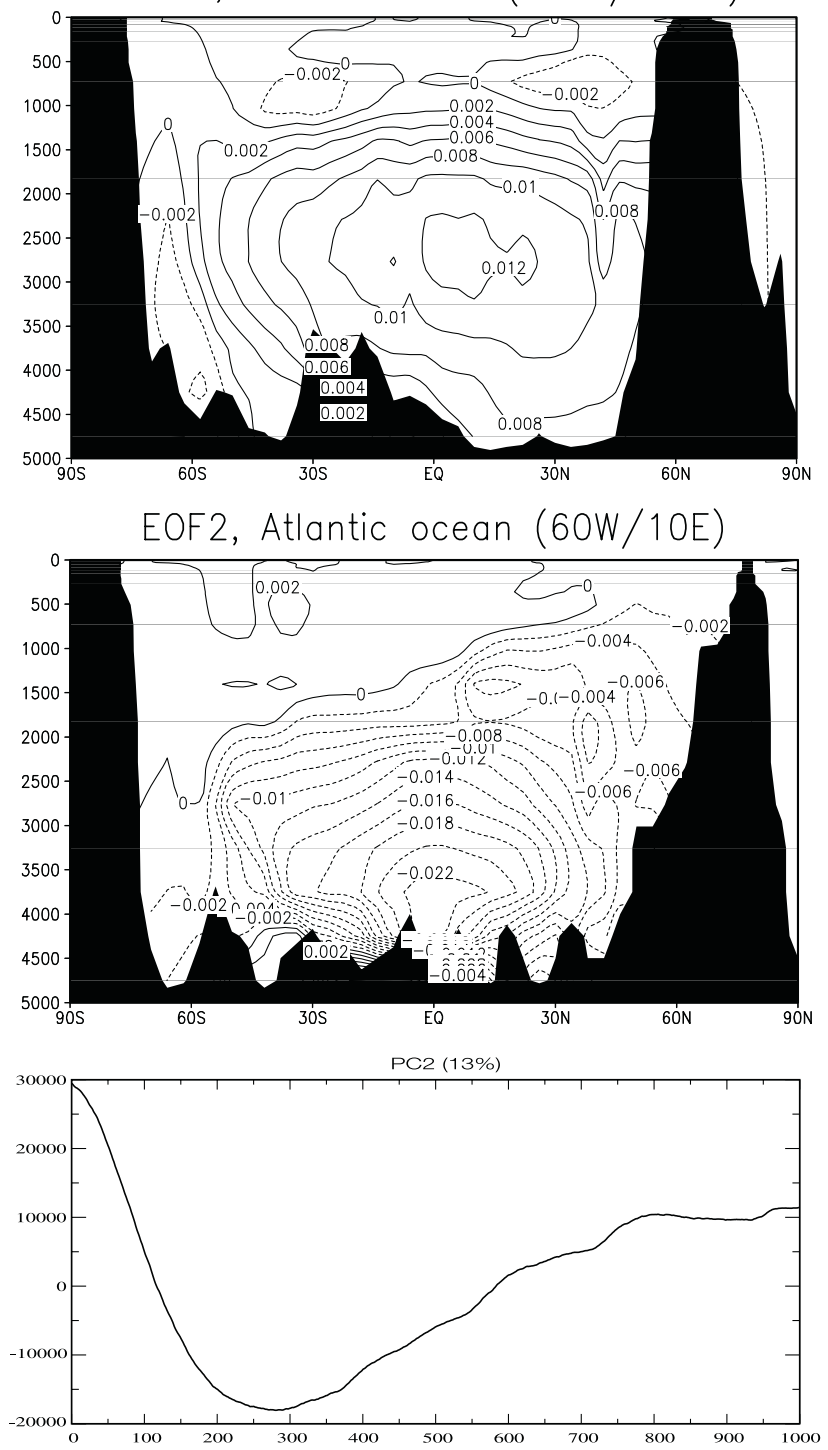

(4) 
Global overturning strm (Sv) 901/1000
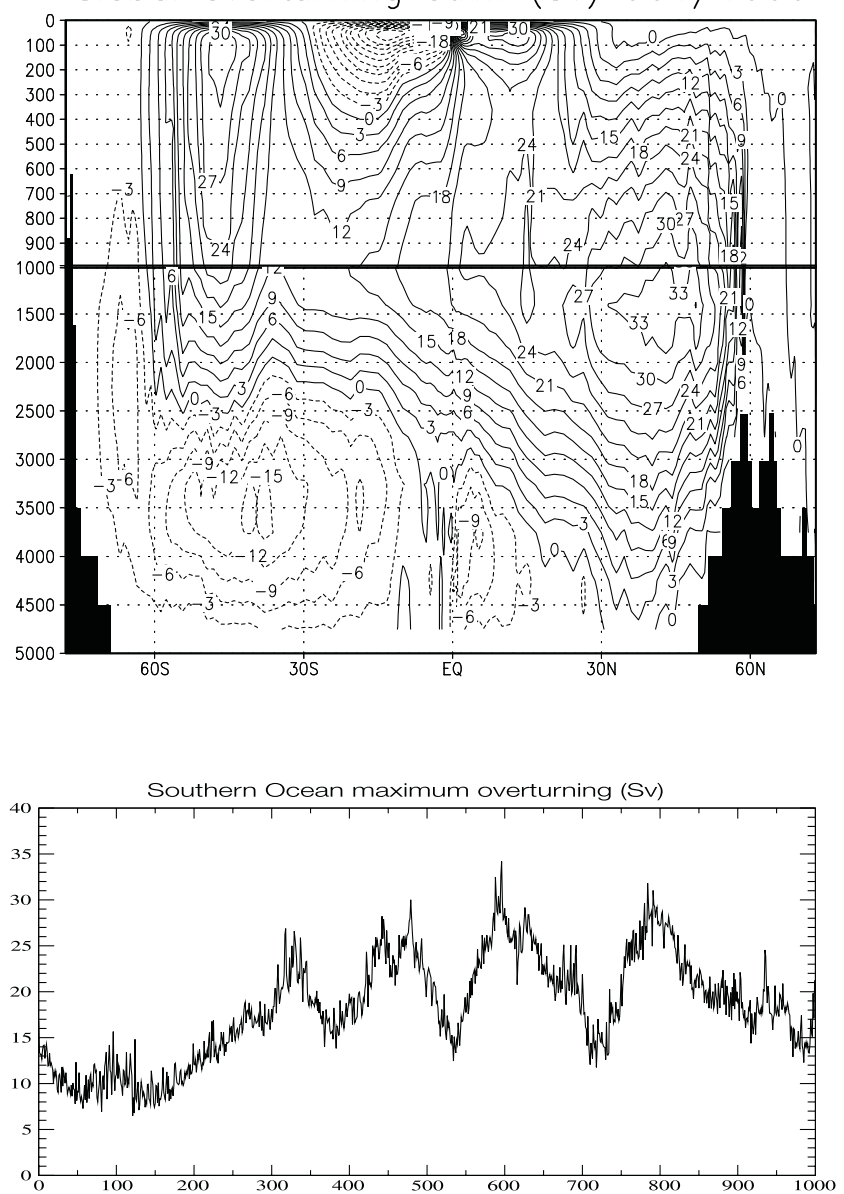

Fig. 5. Top: global overturning circulation mass transport stream function (Sv) averaged for the period 901 to 1000. Bottom: maximum mass transport (Sv) of the Antarctic bottom water in function of simulated year.

the meridional plane. The sense of this transport is clockwise arround high-value centers. At the depth of $3500 \mathrm{~m}$ and around $40^{\circ} \mathrm{S}$, a negative center of $-15 \mathrm{~Sv}$ represents the Antarctic bottom water formation originated mainly in the Ross and Wedell Seas. The bottom panel of fig. 5 plots the time evolution of the maximum overturning mass transport in the Southern Ocean. After the initial drift stage of about 300 years, largeamplitude oscillations can be observed between 12 and 30 Sv. Comparison between this curve and that on the bottom of fig. 1 shows clearly that the Southern Hemisphere SST is very closely related to the overturning circulation. Strong (weak) overturning circulation increases (de- creases) the heat transport from the tropics to the high latitudes and thus increases (decreases) the SST of the high latitudes.

Let us now examine two periods with extreme values of overturning circulation. The 20 -year averaged period from 770 to 789 is characterized by a strong overturning circulation. However the period from 721 to 740 has a weak overturning circulation. The top panel of fig. 6 shows the difference of overturning stream function be-
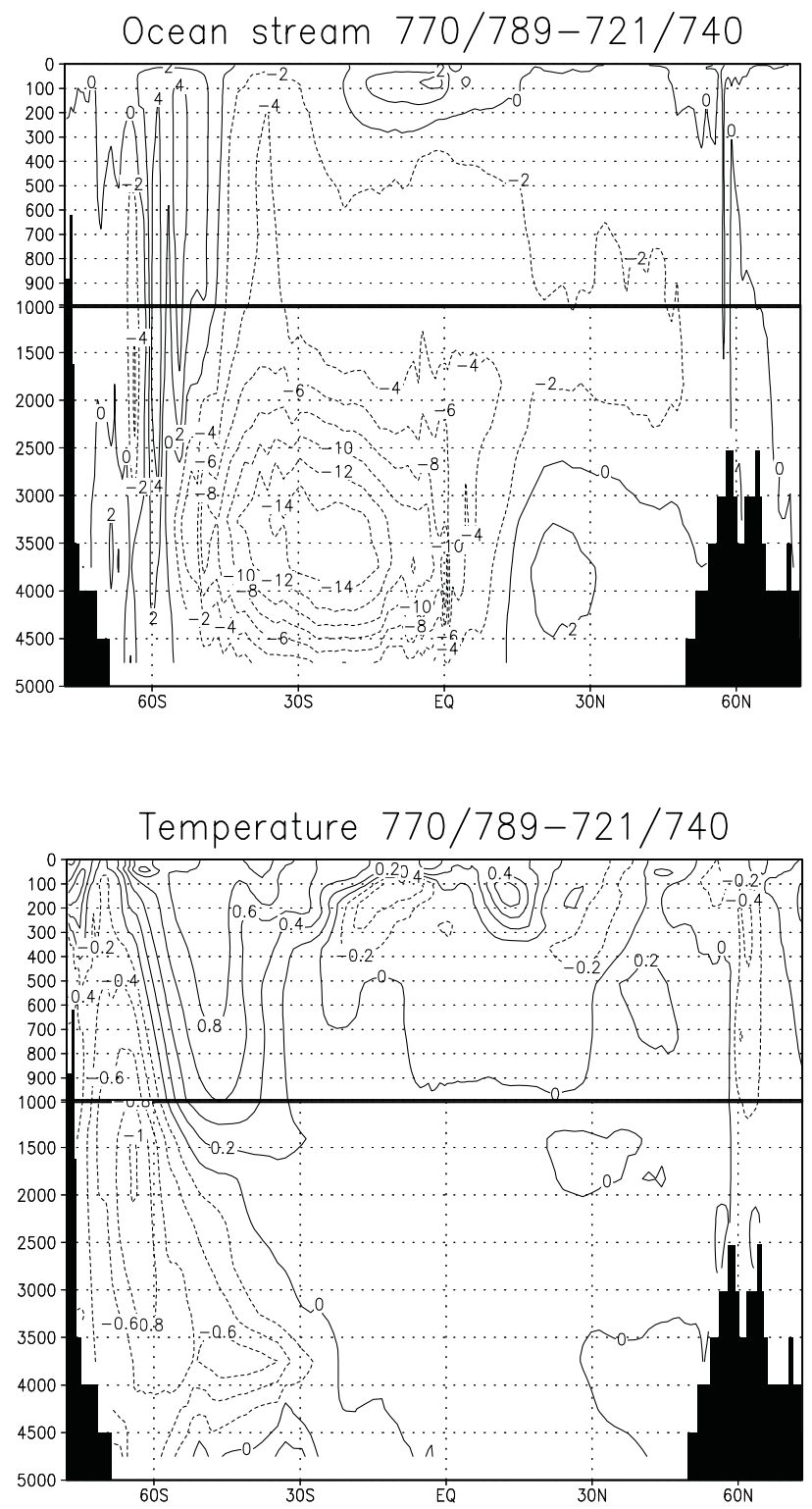

Fig. 6. Difference for two extreme periods (770/789721/740). Top: global overturning stream function (Sv). Bottom: oceanic temperature $\left({ }^{\circ} \mathrm{C}\right)$. 

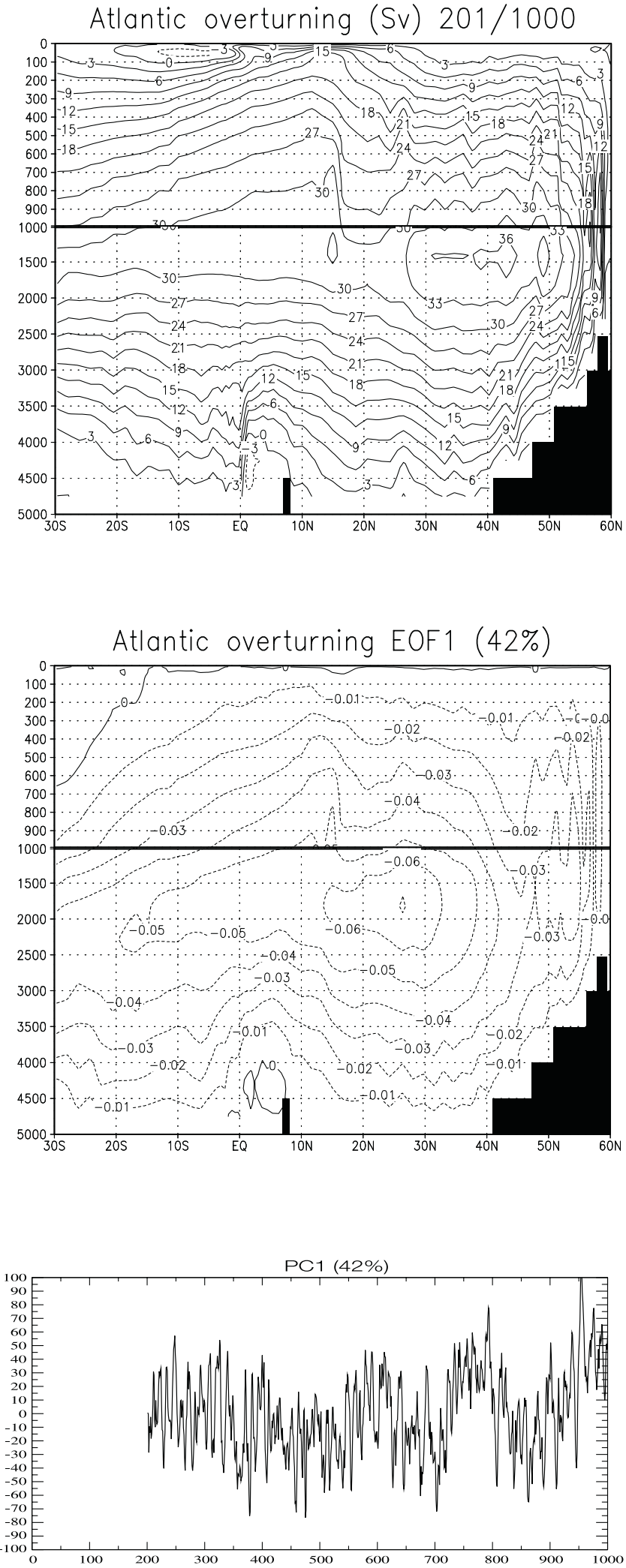

Fig. 7. Top: North Atlantic overturning stream function (Sv) for years 201 to 1000. Middle: leading EOF structure. Bottom: corresponding time series. The middle and bottom panels have arbitrary units. tween these two periods (strong-weak). The difference value in the center $(14 \mathrm{~Sv})$ is of the same order of the field itself. It is also closer to the equator, showing an extension of the Antarctic bottom water. The bottom panel of fig. 6 shows the difference of the zonally-averaged oceanic temperature between the two periods. For the zone from 30 to $60^{\circ} \mathrm{S}$ and from the surface to arround $1500 \mathrm{~m}$, warm water $\left(0.8^{\circ} \mathrm{C}\right)$ is observed. However in the south and under the bottom of this zone, cold water (until $-1^{\circ} \mathrm{C}$ ) is observed. This is coherent with the fact that the deep convection is driven by cold and dense water.

The North Atlantic overturning mass transport stream function is shown in the top panel of fig. 7 for the period averaged from the year 201 to 1000 . The maximum value of the stream function is $36 \mathrm{~Sv}$ at the depth of $1500 \mathrm{~m}$ and at $40^{\circ} \mathrm{N}$, showing a slightly too intense North Atlantic Deep Water cell. We should note that the Mediterranean contribution was taken into account in the calculation. To get the coherent structure for the variation of the Atlantic overturning circulation, we performed an EOF analysis to the annual mean values for the period from 201 to 1000. The leading EOF (accounting for $42 \%$ of the total variance) is plotted in the middle panel of fig. 7. It is a monpole structure, quite similar to the field itself, indicating that the North Atlantic Deep Water cell has a dominant stationnary oscillation. The time series (PC, shown in the bottom panel of fig. 7) reveals that important decadal-scale variations exist. Lowfrequencies at centennial scale can also be identified through visual inspection.

\section{Conclusions}

A 1000-year ocean-atmosphere coupled simulation was presented in this paper. It is the first time that the IPSL coupled model, without any artificial flux adjustment, has been run for such a long period. The results are very encouraging since the model's drift is relatively small at the end of the simulation and no systematic drift tendancy is observed.

For the global SST, there is a warming in the high latitudes of the two hemispheres. However the mid latitudes have a cooling belt. The tropical 
Indian Ocean is quite realistic. The warm pool is slightly eroded by the cold tongue and thus a little cold. The tropical Atlantic has a more important cooling. For the eastern part of the subtropical oceanic basins, the traditional warming is much reduced in the Atlantic, but remains important in the Pacific. Our results shows that the model's initial drift during the first ten years is a very important indicator for the longer time-scale behaviour, this is useful for future coupled model development.

We have also studied the SST evolution for different regions of the globe, a remarkable phenomenon is the quick SST changes in the Southern Hemisphere, also visible in the global mean SST. The variation of $0.4^{\circ} \mathrm{C}$ can be obtained during approximately 50 years for the global mean. This variation is closely related to the deep convection in the Southern Ocean. The meridional overturning mass transport varies from 12 to $30 \mathrm{~Sv}$, making the heat transport from the equator very different. It is possible that the variation of the overturning circulation is due to the interactive coupling between the atmosphere and the ocean for the hydrological cycle. Further studies are needed to confirm this point.

Our results have also implication for the anthropogenic global warming detection. In fact, the quick global mean SST variation, $0.4^{\circ} \mathrm{C}$, due to the Southern Ocean overturning circulation is almost comparable with the observed global warming $\left(0.6^{\circ} \mathrm{C}\right)$ since the beginning of the industrial era (IPCC, 2001). This implies that the climate natural variability can be large and the global warming detection is indeed a very difficult issue. However, this result should be considered with caution since our model currently does not include the seaice component which can play an important role in the high-latitudes deep oceanic convection.

\section{Acknowledgements}

The authors wish to thank the scientific and technique teams at CERFACS, LMD and LODYC who have developed the GCMs and the coupler. Computer ressources were kindly provided by the IDRIS, the computer center of the CNRS. This work is supported by the European Commission through the SINTEX project.

\section{REFERENCES}

GuAldi, S., A. NAVARRA, E. Guilyardi and P. DELECluse (2003): Assessment of the tropical Indo-Pacific climate in the SINTEX CGCM, Ann. Geophysics, 46 (1), 1-26 (this volume).

GuILYARDI, E., G. MADEC and L. TERRAY (2001): The role of lateral ocean physics in the upper ocean thermal balance of a coupled ocean-atmosphere GCM, Climate Dyn., 17, 589-599.

IPCC (Intergovernmental Panel on Climate Change) (2001): Observed climate variability and change, in Climate Change 2001, the Scientific Basis, (Cambridge University Press), 99-181.

LE Treut, H. and Z.X. Li (1991): Sensitivity of an atmospheric general circulation model to prescribed SST changes: feedback effects associated with the simulation of cloud optical properties, Climate Dyn., 5, 175-187.

LEVITUS S. (1982): Climatological Atlas of the world ocean, NOAA professional paper $n .13$, pp. 173.

LI, Z.X. (1999): Ensemble atmospheric GCM simulation of climate interannual variability from 1979 to 1994 , J. Climate, 12, 986-1001.

MAdeC, G., P. DeleCluse, M. IMBARD and C. LeVy (1998): OPA version 8.1 ocean general circulation model reference manual, Note IPSL n.11, available at IPSL, Paris.

RAYNER, N.A., D.E. PARKER, E.B. HORTON, C.K. FollAND, L.V. ALEXANDER and P. FRICH (2000): The HadISST1 global sea-ice and sea surface temperature dataset, 18711999, Hadley Centre Technical Note 17.

SADOURNY, R. and K. LAVAL (1984): January and July Performance of the LMD General Circulation model in New Perspectives in Climate Modelling, edited by A. BERGER and C. NICOLIS (Elsevier), 173-198.

VAlcke, S., L. Terray and A. PiACEnTINI (2000): The OASIS coupler user guide version 2.4, Technical Report $T R / C M G C / 00-10$, available at Cerfacs, Toulouse, France. 